\title{
Miss rate of colorectal neoplastic polyps and risk factors for missed polyps in consecutive colonoscopies
}

\author{
Nam Hee Kim*, Yoon Suk Jung*, Woo Shin Jeong, Hyo-Joon Yang, Soo-Kyung Park, Kyuyong Choi, Dong Il Park \\ Division of Gastroenterology, Department of Internal Medicine, Kangbuk Samsung Hospital, Sungkyunkwan University School of Medicine, \\ Seoul, Korea
}

Background/Aims: Colonoscopic polypectomy is the best diagnostic and therapeutic tool to detect and prevent colorectal neoplasms. However, previous studies have reported that $17 \%$ to $28 \%$ of colorectal polyps are missed during colonoscopy. We investigated the miss rate of neoplastic polyps and the factors associated with missed polyps from quality-adjusted consecutive colonoscopies. Methods: We reviewed the medical records of patients who were found to have colorectal polyps at a medical examination center of the Kangbuk Samsung Hospital between March 2012 and February 2013. Patients who were referred to a single tertiary academic medical center and underwent colonoscopic polypectomy on the same day were enrolled in our study. The odds ratios (ORs) associated with polyp-related and patient-related factors were evaluated using logistic regression analyses. Results: A total of 463 patients and 1,294 neoplastic polyps were analyzed. The miss rates for adenomas, advanced adenomas, and carcinomas were $24.1 \%(312 / 1,294), 1.2 \%(15 / 1,294)$, and $0 \%(0 / 1,294)$, respectively. Flat/sessile-shaped adenomas (adjusted OR, 3.62; 95\% confidence interval [CI], 2.40-5.46) and smaller adenomas (adjusted OR, 5.63; 95\% CI, 2.8411.15 for $\leq 5 \mathrm{~mm}$; adjusted OR, 3.18; 95\% CI, 1.60-6.30 for 6-9 mm, respectively) were more frequently missed than pedunculated/sub-pedunculated adenomas and larger adenomas. In patients with 2 or more polyps compared with only one detected (adjusted OR, 2.37; 95\% CI, 1.55-3.61 for 2-4 polyps; adjusted OR, 11.52; 95\% CI, 4.61-28.79 for $\geq 5$ polyps, respectively) during the first endoscopy, the risk of missing an additional polyp was significantly higher. Conclusions: One-quarter of neoplastic polyps was missed during colonoscopy. We encourage endoscopists to detect smaller and flat or sessile polyps by using the optimal withdrawal technique. (Intest Res 2017;15:411-418)

Key Words: Colorectal polyp; Miss rate; Consecutive colonoscopies

\section{INTRODUCTION}

The National Polyp Study (NPS) was the first to report that colonoscopic polypectomy reduced the incidence of colorectal cancer. ${ }^{1}$ A recent, long-term, follow-up cohort study of the NPS demonstrated that colonoscopic removal of adenomatous polyps prevents death from colorectal can-

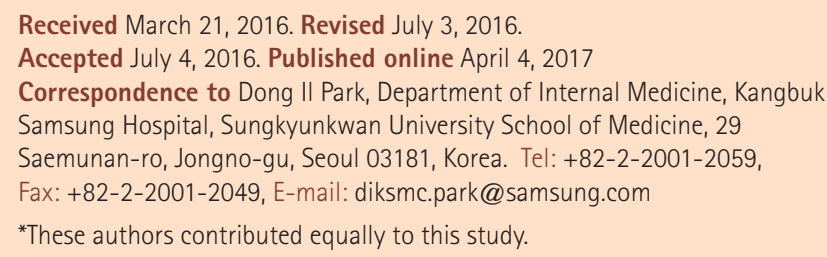

Financial support: None. Conflict of interest: None. cer. ${ }^{2}$ Colonoscopic polypectomy is the best diagnostic and therapeutic tool to detect and prevent colorectal neoplasms. Nevertheless, interval cancers occur, especially in the right colon, and the rate of interval cancer has been reported to be approximately $2 \%$ to $6 \%{ }^{3,4}$ There are several possible reasons for the occurrence of interval cancers after negative colonoscopy, including biological variation in tumor growth rates, incomplete removal of polyps, inadequate bowel preparation, technical limitations, and suboptimal examination techniques. ${ }^{5,6}$ To reduce interval cancers, quality assurance programs have been introduced worldwide. Cecal intubation, adequate bowel preparation, and a colonoscopic withdrawal time of 6 minutes or more are suggested to ensure complete removal of polyps and improvement of polyp detection based on previous studies. ${ }^{7.8}$ Despite these efforts,

\footnotetext{
๑ Copyright 2017. Korean Association for the Study of Intestinal Diseases. All rights reserved.

This is an Open Access article distributed under the terms of the Creative Commons Attribution Non-Commercial License (http://creativecommons.org/licenses/by-nc/4.0)

which permits unrestricted non-commercial use, distribution, and reproduction in any medium, provided the original work is properly cited.
} 
it has been reported that a significant number of polyps are missed during surveillance colonoscopy, ${ }^{9-17}$ thereby leading to the development of interval cancers from the missed neoplastic polyps. ${ }^{18}$ Based on several tandem or consecutive colonoscopy studies, ${ }^{9,12-15}$ the miss rate of polyps is reported to be $16.8 \%$ to $28 \%$. However, these studies had several limitations, such as small polyp and patient sample sizes, repeat use of examiners, high variability in time between the 2 procedures (more than 1 day, up to 3 months), or heterogeneity in study design (e.g., different colonoscopy device used for the patient's 2 procedures). Additionally, data on risk factors for missing polyps during colonoscopy are extremely limited.

We performed this retrospective study to investigate the miss rate of neoplastic polyps using quality-adjusted, same-day, consecutive colonoscopies. We also analyzed the characteristics of missed neoplastic polyps and patients with missed polyps to determine polyp-related and patientrelated factors that influence the likelihood of missed polyps.

\section{METHODS}

\section{Study Population}

Study subjects visited the Comprehensive Medical Examination Center of the Kangbuk Samsung Hospital and underwent colonoscopy as part of a regular health check-up between March 2012 and February 2013. Before undergoing surveillance colonoscopy, all subjects were asked to complete a questionnaire independently. The questionnaire included demographic characteristics, medical history, and surgical history. Old age was defined as 60 years or older and obesity was defined as having a BMI $\geq 25 \mathrm{~kg} / \mathrm{m}^{2}$. All surveillance colonoscopies were performed by 13 colonoscopists who had each performed at least 1,000 colonoscopies. The colonoscopists at this medical examination center usually do not perform therapeutic colonoscopies, with the exception of diminutive polyp removal with biopsy forceps. Patients who had polyps that were $5 \mathrm{~mm}$ or larger and who wanted to undergo a polypectomy on the same day were referred to the endoscopy center at the Kangbuk Samsung Hospital within hours of the first procedure. A total of 669 patients were referred for polypectomy and provided informed consent. Patients were excluded if they met one of the following criteria: cecal intubation failure, poor bowel preparation, ${ }^{19}$ withdrawal time of 6 minutes or less from the surveillance colonoscopy, or history of bowel resection or IBD.

\section{Consecutive Colonoscopy and Polypectomy}

Patients referred from the Comprehensive Medical Examination Center underwent same-day, consecutive colonoscopies and polypectomy performed by one of 9 colonoscopists who had performed at least 1,000 colonoscopies. All endoscopists were staff members and senior fellows who performed colonoscopies not only for screening but also for endoscopic therapy. All colorectal polyps found during the consecutive colonoscopies were completely removed by biopsy forceps, endoscopic mucosal resection, or endoscopic submucosal dissection. Non-missed polyps were defined as polyps found during both the first colonoscopy and the second colonoscopy; missed polyps were defined as polyps found only during the second colonoscopy.

Bowel cleansing was accomplished by using $4 \mathrm{~L}$ of polyethylene glycol (Taejoon Pharm, Seoul, Korea). The quality of bowel preparation was assessed by the Aronchick scale as excellent (a small volume of clear liquid or more than $95 \%$ of the surface seen), good (a large volume of clear liquid covering $5 \%$ to $25 \%$ of the surface but more than $90 \%$ of the surface was seen), fair (some semi-solid stool that could be suctioned or washed away but more than $90 \%$ of the surface was seen), or poor (semi-solid stool that could not be suctioned or washed away and less than $90 \%$ of the surface was seen). ${ }^{15}$

Conventional colonoscopes (CF-Q260AI and CF-H260AI; Olympus Medical Systems, Tokyo, Japan; same models as used during the first colonoscopy) were used for all procedures. Procedures were performed with the patient under conscious sedation. The colonoscopists who performed consecutive colonoscopies often used a transparent cap (D201-13404 or D-201-14304; Olympus Medical Systems) to detect polyps more easily.

All polyps were described by their location, shape, and size. Polyps of the cecum, the ascending colon, or the transverse colon were defined as polyps of the right colon, and those found in the descending colon, the sigmoid colon, or the rectum were defined as polyps of the left colon. Polyp shape was classified either as pedunculated or sub-pedunculated or as flat or sessile. Polyp size was measured indirectly with biopsy forceps and was recorded as $\leq 5 \mathrm{~mm}, 6$ to 9 $\mathrm{mm}$, or $\geq 10 \mathrm{~mm}$.

All endoscopically removed specimens were reviewed by 5 experienced gastrointestinal pathologists. We limited our analyses to only neoplastic polyps, and excluded inflammatory polyps, hyperplastic polyps, and subepithelial lesions. Neoplastic polyps included traditional or sessile serrated ad- 
enomas; tubular, villous, or tubulovillous adenomas; and carcinomas. Advanced adenoma was defined as the presence of one of the following features: $>10 \mathrm{~mm}$ diameter, tubulovillous or villous structure, and high-grade dysplasia.

\section{Calculation of Miss Rate}

The miss rates were calculated for overall neoplastic polyps, adenomas, advanced adenomas, and carcinomas, respectively. After the 2 consecutive colonoscopies had been completed, we categorized the missed neoplastic polyps according to their location, shape, and size. The miss rate of adenomas was defined as the proportion of missed adenomas among all neoplastic polyps. The miss rate of advanced adenomas was defined as the proportion of missed advanced adenomas among all neoplastic polyps. A per-patient miss rate was calculated as the number of patients with at least one neoplastic polyp missed by the first colonoscopy divided by the number of patients with at least one neoplastic polyp found during either the first or the second colonoscopy. ${ }^{13}$

\section{Statistical Analyses}

The Student $t$-test was used to compare numerical variables between groups. The chi-square or Fisher exact test was used to compare categorical variables. The multivariate logistic regression model was used to identify independent variables associated with missed polyps or patients with missed polyps. ORs and 95\% CIs and their associated $P$ values were calculated for per-polyp and per-patient associations. Values were considered statistically significant when
$P<0.05$. All statistics were performed using predictive analytics software PASW version 18.0 (SPSS Inc., Chicago, IL, USA).

\section{Ethics}

This study was conducted in accordance with the principles of the Helsinki Declaration. The Institutional Review Board of Kangbuk Samsung Hospital approved this study, and informed consent was obtained from all subjects.

\section{RESULTS}

\section{Study Subjects}

A total of 620 patients underwent colonoscopy as part of their regular health check-up and were subsequently referred for colonoscopic polypectomy. Ninety-one patients were excluded because of cecal intubation failure $(n=3)$, poor bowel preparation $(\mathrm{n}=81)$, or termination of the examination because there were too many polyps to proceed $(\mathrm{n}=7)$. Thus, 529 patients who underwent consecutive colonoscopies and polypectomy were enrolled. Of these patients, 66 had only non-neoplastic polyps (inflammatory polyps, hyperplastic polyps, or subepithelial lesions); these patients were excluded from the final analysis. Ultimately, 463 patients were included in the final analysis of the rate of and risk factors for missed neoplastic polyps (Fig. 1). Among the 463 patients enrolled, 381 (82.3\%) were male. The mean age was $49.8 \pm 9.8$ years and the mean BMI was $24.6 \pm 3.1$ $\mathrm{kg} / \mathrm{m}^{2}$. Bowel preparation was described as excellent for $112(24.2 \%)$, good for 294 (63.5\%), and fair for 57 patients

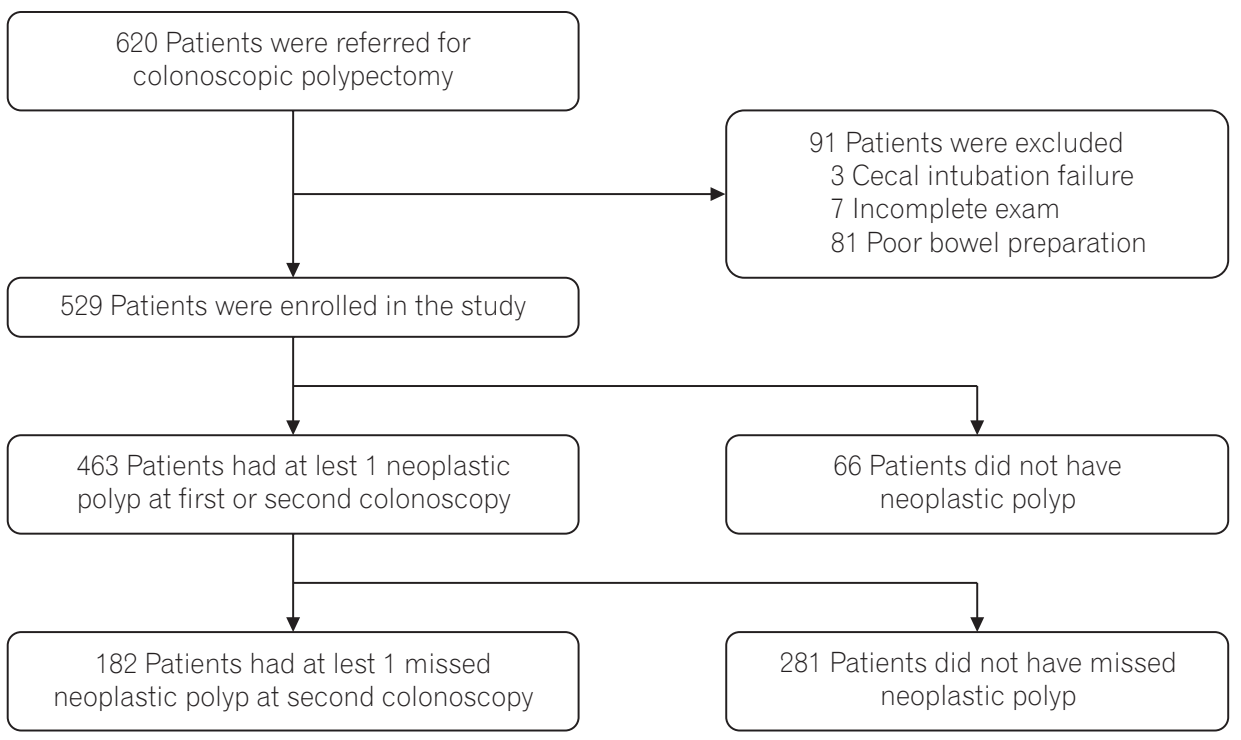

Fig. 1. Flow diagram illustrating the selection of study subjects. 
(12.3\%). The median duration of withdrawal time for the first colonoscopy was 8.5 minutes (range, $6-22$ minutes). Interval time between the first and second colonoscopies was short (mean, $2.4 \pm 0.8$ hours).

\section{Polyp Characteristics}

Overall, 1,368 polyps and 5 subepithelial lesions (neuroendocrine tumors or leiomyomas) were detected during the consecutive colonoscopies. Of 1,368 polyps, 1,294 were neoplastic polyps (1,287 adenomas, 235 advanced adenomas, and 7 carcinomas). The adenomas included tubular adenomas $(\mathrm{n}=1,247)$, tubulovillous adenomas $(\mathrm{n}=7)$, and serrated adenomas ( $\mathrm{n}=33)$. Dysplasia of adenoma was classified as either low-grade $(n=1,270)$ or high-grade $(n=17)$. Neoplastic polyp location was classified as being in the ascending colon ( $\mathrm{n}=313)$, transverse colon $(\mathrm{n}=344)$, descending colon $(n=171)$, sigmoid colon $(n=342)$, or rectum $(n=124)$. In other words, 657 polyps were on the right colon and 637 polyps were on the left colon. Neoplastic polyp shape was classified either as pedunculated or subpedunculated $(n=442)$ or as flat or sessile $(\mathrm{n}=852)$. Neoplastic polyp size was recorded as $\leq 5 \mathrm{~mm}$ ( $\mathrm{n}=604), 6$ to $9 \mathrm{~mm}(\mathrm{n}=464)$, and $\geq 10 \mathrm{~mm}(\mathrm{n}=226)$ (Fig. 2).

\section{Polyp Miss Rate and Polyp-Related Factors}

Among all 1,294 neoplastic polyps that were detected during the first and second colonoscopies, 312 of these were detected only during the second colonoscopy. The miss rate for adenomas was $24.1 \%(312 / 1,294)$ and the miss rate

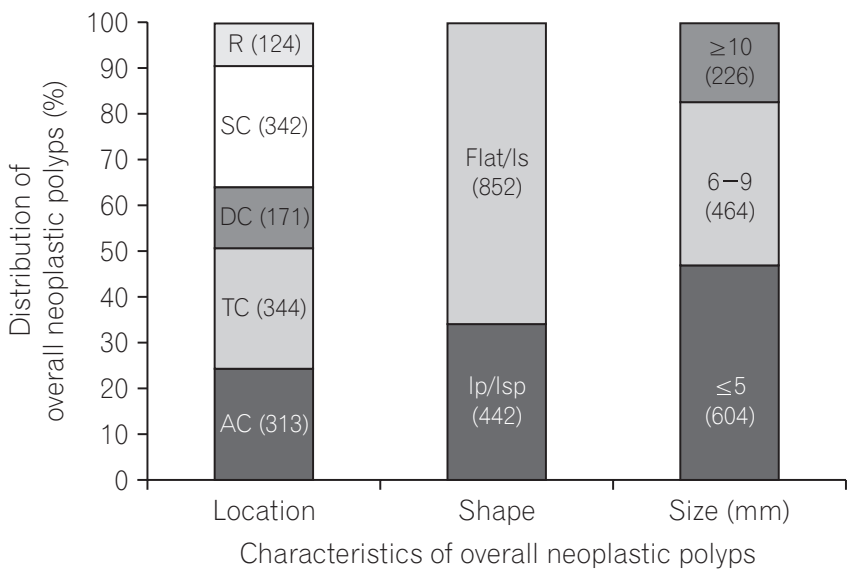

Fig. 2. Characteristics of overall neoplastic polyps detected during the first or second colonoscopy. $\mathrm{R}$, rectum; SC, sigmoid colon; DC, descending colon; TC, transverse colon; $A C$, ascending colon; Is, sessile type; Ip, pedunculated type; Isp, subpedunculated type. for advanced adenomas was $1.2 \%(15 / 1,294)$, respectively. There were no carcinomas that were missed during the first colonoscopy.

Polyp factors associated with missed lesions are shown in Table 1. The miss rates for polyps located on the right colon and left colon were $26.8 \%$ and $21.4 \%$, respectively. The risk of missing neoplastic polyps on the right colon was higher than that for missing those on the left colon, but not significantly so after adjusting for other factors (adjusted OR, 1.25; 95\% CI, 0.96-1.64). The miss rates for pedunculated or subpedunculated polyps and for flat or sessile polyps were $7.5 \%$ and $32.7 \%$, respectively. Flat or sessile polyps were missed more frequently than pedunculated or subpedunculated polyps (adjusted OR, 3.62; 95\% CI, 2.40-5.46). The miss rates of $\leq 5 \mathrm{~mm}, 6$ to $9 \mathrm{~mm}$, and $\geq 10 \mathrm{~mm}$ polyps were $35.4 \%, 18.8 \%$, and $4.9 \%$, respectively. The risk of missing neoplastic polyps 6 to $9 \mathrm{~mm}$ and $\leq 5 \mathrm{~mm}$ was significantly higher compared with the risk of missing neoplastic polyps that were $\geq 10 \mathrm{~mm}$ (adjusted OR, 3.18; 95\% CI, 1.60-6.30; adjusted OR, 5.63; 95\% CI, 2.84-11.15, respectively).

The total number of missed advanced adenomas was 15 . The proportion of missed advanced adenomas was higher for the right colon, flat or sessile polyps, and polyps $\geq 10 \mathrm{~mm}$ than for the left colon, pedunculated or sub-pedunculated polyps, and polyps $<10 \mathrm{~mm}$ ( 10 vs. 5,12 vs. 3 , and 11 vs. 4 , respectively).

\section{Per-Patient Miss Rate and Patient-Related Factors}

Among the 463 total patients with at least one neoplastic polyp found during the first or second colonoscopy, 182 (39.3\%) were found to have at least one missed neoplastic polyp during the second colonoscopy. The per-patient miss rates of adenomas, advanced adenomas, and carcinomas were $39.7 \%, 6.1 \%$, and $0 \%$, respectively (Table 2 ).

Patient factors associated with missed lesions are shown in Table 3. Only the number of neoplastic polyps found during the first colonoscopy was independently associated with the per-patient miss rate. In patients with 2 or more polyps (especially 5 or more polyps) detected during the first endoscopy, the risk of missing an additional polyp increased significantly (adjusted OR, 2.37; 95\% CI, 1.55-3.61; adjusted OR, 11.52; 95\% CI, 4.61-28.79 when comparing 0-1 polyp with $2-4$ polyps and $\geq 5$ polyps, respectively). Sex, age, BMI, quality of bowel preparation, withdrawal time during the first colonoscopy, and transparent cap use during the second colonoscopy did not affect the per-patient miss rate. 
Table 1. Characteristics of Missed Neoplastic Polyps and Polyp-Related Factors Affected by Missed Neoplastic Polyps

\begin{tabular}{|c|c|c|c|c|}
\hline & \multirow{2}{*}{$\begin{array}{c}\text { Non-missed neoplastic } \\
\text { polyp }(n=982)\end{array}$} & \multirow{2}{*}{$\begin{array}{l}\text { Missed neoplastic polyp } \\
\qquad(n=312)\end{array}$} & Univariate & \multirow{2}{*}{$\begin{array}{l}\text { Multivariate }^{a} \\
\text { OR }(95 \% \mathrm{Cl})\end{array}$} \\
\hline & & & OR $(95 \% \mathrm{Cl})$ & \\
\hline \multicolumn{5}{|l|}{ Location } \\
\hline Left colon & $501(51.0)$ & 136 (43.6) & 1.0 & 1.0 \\
\hline Right colon & $481(49.0)$ & $176(56.4)$ & $1.35(1.04-1.74)^{b}$ & $1.25(0.96-1.64)$ \\
\hline \multicolumn{5}{|l|}{ Shape } \\
\hline Ip or Isp & 409 (41.6) & 33 (10.6) & 1.0 & 1.0 \\
\hline Flat or Is & $573(58.4)$ & $279(89.4)$ & $6.04(4.12-8.85)^{b}$ & $3.62(2.40-5.46)^{b}$ \\
\hline \multicolumn{5}{|l|}{ Size $(\mathrm{mm})$} \\
\hline$\geq 10$ & 215 (21.9) & $11(3.5)$ & 1.0 & 1.0 \\
\hline $6-9$ & 377 (38.4) & 87 (27.9) & $4.51(2.36-8.63)^{b}$ & $3.18(1.60-6.30)^{b}$ \\
\hline$\leq 5$ & 390 (39.7) & $214(68.6)$ & $10.73(5.72-20.11)^{b}$ & $5.63(2.84-11.15)^{b}$ \\
\hline \multicolumn{5}{|l|}{ Histology } \\
\hline Tubular & 940 (95.7) & 307 (98.4) & NA & NA \\
\hline Tubulovillous & $7(0.7)$ & 0 & & \\
\hline Serrated & $28(2.9)$ & $5(1.6)$ & & \\
\hline Carcinoma & $7(0.7)$ & 0 & & \\
\hline \multicolumn{5}{|l|}{ Dysplasia } \\
\hline Low & 963 (98.1) & 307 (98.4) & NA & NA \\
\hline High & $12(1.2)$ & $5(1.6)$ & & \\
\hline Carcinoma & $7(0.7)$ & 0 & & \\
\hline
\end{tabular}

Values are presented as number (\%).

${ }^{a}$ Adjusted for location, shape, and size.

${ }^{b} P<0.05$.

Ip, pedunculated type; Isp, subpedunculated type; Is, sessile type; NA, not available.

Table 2. The Per-Patient Miss Rate of Neoplastic Polyps at First Colonoscopy

\begin{tabular}{lccc}
\hline & $\begin{array}{c}\text { Patients with at least 1 } \\
\text { neoplastic polyp }\end{array}$ & $\begin{array}{c}\text { Patients with at least 1 } \\
\text { missed neoplastic polyp }\end{array}$ & $\begin{array}{c}\text { Per-patient } \\
\text { miss rate (\%) }\end{array}$ \\
\hline Overall neoplastic polyp & 463 & 182 & 39.3 \\
Adenoma & 459 & 182 & 39.7 \\
Advanced adenoma & 180 & 11 & 6.1 \\
Carcinoma & 7 & 0 & 0 \\
\hline
\end{tabular}

\section{DISCUSSION}

In this quality-adjusted, consecutive colonoscopy study, we found that the miss rate for adenomas was $24.1 \%$ and that for advanced adenomas was $1.2 \%$. Flat or sessile shape and small size $(<10 \mathrm{~mm})$ were independent risk factors for missed adenomas. With regard to patient-related factors, patients with 2 or more polyps during the first colonoscopy had a higher miss rate.
Several previous studies reported that the miss rates for total polyps, adenomas, and advanced adenomas were $16.8 \%$ to $28 \%, 16 \%$ to $26 \%$, and $1.7 \%$ to $11 \%$, respectively. ${ }^{9-15,17}$ The variation in adenoma miss rates between studies may be caused by heterogeneity in study design. The adenoma miss rates found in our study were comparable to previously published results. However, we suspect that the miss rate from our study is lower than that of previous studies because we excluded patients with cecal intubation failure, poor bowel 
Table 3. Patient-Related Factors Affected with Missed Neoplastic Polyps

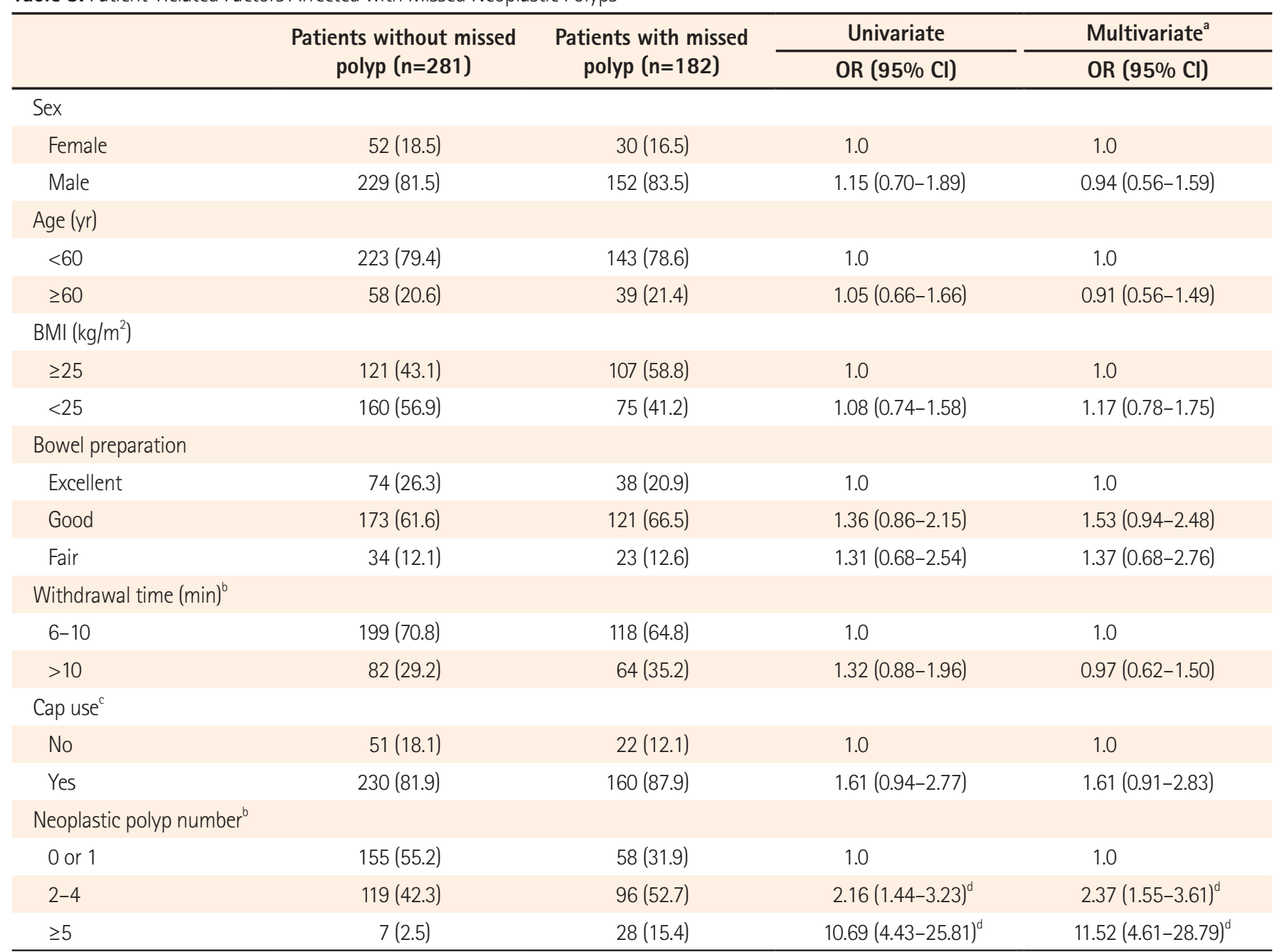

Values are presented as number (\%).

${ }^{a}$ Adjusted for sex, age, BMI, bowel preparation scale, withdrawal time, cap use, and neoplastic polyp number.

bithdrawal time and neoplastic polyp number during first colonoscopy.

${ }^{\mathrm{c}} \mathrm{Cap}$ use during second colonoscopy.

${ }^{\mathrm{d}} P<0.05$.

preparation, and a withdrawal time of 6 minutes or less at the first examination for colonoscopic quality adjustment. ${ }^{6}$ Contrary to expectations, our study's miss rate for adenoma was not lower than those of previous studies; instead, it was slightly higher. One possible reason may be the use of the transparent cap during the second colonoscopy. More than $80 \%$ of patients in our study underwent transparent cap-assisted colonoscopy. The use of the transparent cap has been known to improve polyp detection and shorten the time required for cecal intubation in several studies. ${ }^{20,21}$ Although use of the transparent cap during the second colonoscopy was not significantly associated with the per-patient miss rate in our study, we think that it might contribute to an in- creased miss rate.

In the present study, polyp shape, size, and number of polyps found during the first colonoscopy were associated with the miss rate. We found that flat or sessile polyps were missed significantly more often than pedunculated or subpedunculated polyps. Similarly, Heresbach et al. ${ }^{13}$ reported that sessile or flat polyps were significantly associated with a higher miss rate. These results suggest that the present colonoscopic technique is insufficient for the detection of flat lesions. Special colonoscopic techniques, such as narrow band imaging, autofluorescence, chromoendoscopy, and third-eye retroscope, should be considered as alternatives to improve detection of flat polyps. 
In our study, smaller neoplastic polyps $(<10 \mathrm{~mm}$, especially $\leq 5 \mathrm{~mm}$ ) were more frequently missed than large neoplastic polyps ( $\geq 10 \mathrm{~mm}$ ). Polyp size has also been associated with miss rate in other studies. Several previous studies have also found that the miss rate increases significantly in smaller polyps. ${ }^{9,12,13,17}$ A systematic review that included 6 tandem colonoscopy studies with a total of 465 patients reported that colonoscopy rarely misses polyps $\geq 10 \mathrm{~mm}$, but the miss rate increases significantly for smaller polyps. ${ }^{9}$ Heresbach et al. ${ }^{13}$ demonstrated that the diameter (1-mm increments) was associated with a lower miss rate. Diminutive polyps are often neglected because they pose no immediate threat to patients. Although advanced adenomas smaller than 10 mm were very rare in our study, one recent study reported that $10 \%$ of diminutive polyps were advanced adenomas; ${ }^{22}$ therefore, endoscopists also need to focus on the detection of small polyps.

In the present study, the miss rate of neoplastic polyps on the right colon was higher than that for those on the left colon, although the difference was not statistically significant after adjustment. Our findings are consistent with those of Rex et al. ${ }^{23}$ and Ahn et al. ${ }^{12}$ In contrast, Heresbach et al. ${ }^{13}$ and Leufkens et al. ${ }^{14}$ reported a significantly increased miss rate of left-side versus right-side adenomas. In our study, $69 \%$ of neoplastic polyps on the right colon were flat or sessile polyps, and $63 \%$ of neoplastic polyps on the left colon were flat or sessile polyps; therefore, our result may be partly explained by the higher rate of flat lesions on the right colon. A recent study also revealed that nonpolypoid lesions (measuring less than $2.5 \mathrm{~mm}$ in height) were more predominant in the proximal colon. ${ }^{24}$ Moreover, the use of the transparent cap during the second colonoscopy might have increased the detection of flat lesions in the right colon. Our findings may partly explain the observation in previous studies that proximally located adenomas are the main predictor of recurrence of advanced lesions. ${ }^{25,26}$

The greater number of adenomas detected during the initial examination is a significant predictor of a higher adenoma miss rate. ${ }^{12-14,17,23}$ Our study showed that in patients with 2 or more polyps detected during the first endoscopy, the risk of missing an additional polyp was increased. One possible reason for this may be that when the endoscopists at the medical examination center detected the polyps (especially if they detected a large number of polyps), they might not have been very observant or may not have correctly recorded information about polyps because they knew they would refer the patient to follow-up care.
Our study has several limitations. First, most patients who had only diminutive polyps were not included in our study because the colonoscopists of the medical examination center usually removed polyps with biopsy forceps instead of referring the patients for further polypectomy. Therefore, there is a selection bias in this study that may affect our results. Second, a total of 22 endoscopists performed the colonoscopies that were analyzed in our study, which might cause heterogeneity in our results, and we did not analyze for differences between endoscopists. Third, although all endoscopists had performed at least 1,000 colonoscopies, a different endoscopist performed the first and second colonoscopies for each patient. Therefore, the differences in skill, experience, and technique between 2 endoscopists were not controlled for. Finally, because this was not a planned prospective study, it is possible that when the colonoscopists detected the polyps, they might not have meticulously reported detection because they knew they would refer the patient. This might have resulted in an overestimation of the miss rate of neoplastic polyps. However, the strength of our study is that it reflects situations in real clinical practice without the intention of studying missed polyps.

In conclusion, a significant proportion of adenomas were missed by quality-adjusted surveillance colonoscopy. The flat or sessile adenomas and smaller adenomas $(<10$ $\mathrm{mm}$, especially $\leq 5 \mathrm{~mm}$ ) were more frequently missed than pedunculated or subpedunculated adenomas and larger adenomas ( $\geq 10 \mathrm{~mm})$. Additionally, patients with 2 or more neoplastic polyps found during their colonoscopy were more likely to have an additional neoplastic polyp missed. Endoscopists should be careful not to miss small and flat or sessile polyps, and they should focus on the detection of polyps that are difficult to see when some have already been detected during colonoscopy.

\section{REFERENCES}

1. Winawer SJ, Zauber AG, Ho MN, et al. Prevention of colorectal cancer by colonoscopic polypectomy. The National Polyp Study Workgroup. N Engl J Med 1993;329:1977-1981.

2. Zauber AG, Winawer SJ, O'Brien MJ, et al. Colonoscopic polypectomy and long-term prevention of colorectal-cancer deaths. N Engl J Med 2012;366:687-696.

3. Brenner H, Chang-Claude J, Seiler CM, Hoffmeister M. Interval cancers after negative colonoscopy: population-based casecontrol study. Gut 2012;61:1576-1582. 
4. Bressler B, Paszat LF, Chen Z, Rothwell DM, Vinden C, Rabeneck L. Rates of new or missed colorectal cancers after colonoscopy and their risk factors: a population-based analysis. Gastroenterology 2007;132:96-102.

5. Rex DK. Maximizing detection of adenomas and cancers during colonoscopy. Am J Gastroenterol 2006;101:2866-2877.

6. Cha JM. Interval cancers after a negative colonoscopy finding in a Korean population: a small step for gastroenterologists but one giant leap for Koreans. Intest Res 2014;12:169-170.

7. Barclay RL, Vicari JJ, Doughty AS, Johanson JF, Greenlaw RL. Colonoscopic withdrawal times and adenoma detection during screening colonoscopy. N Engl J Med 2006;355:2533-2541.

8. Robertson DJ, Lieberman DA, Winawer SJ, et al. Colorectal cancers soon after colonoscopy: a pooled multicohort analysis. Gut 2014;63:949-956.

9. van Rijn JC, Reitsma JB, Stoker J, Bossuyt PM, van Deventer SJ, Dekker E. Polyp miss rate determined by tandem colonoscopy: a systematic review. Am J Gastroenterol 2006;101:343-350.

10. Shehadeh I, Rebala S, Kumar R, Markert RJ, Barde C, Gopalswamy N. Retrospective analysis of missed advanced adenomas on surveillance colonoscopy. Am J Gastroenterol 2002;97:11431147.

11. Kasugai K, Miyata M, Hashimoto T, et al. Assessment of miss and incidence rates of neoplastic polyps at colonoscopy. Dig Endosc 2005; 17:44-49.

12. Ahn SB, Han DS, Bae JH, Byun TJ, Kim JP, Eun CS. The miss rate for colorectal adenoma determined by quality-adjusted, backto-back colonoscopies. Gut Liver 2012;6:64-70.

13. Heresbach D, Barrioz T, Lapalus MG, et al. Miss rate for colorectal neoplastic polyps: a prospective multicenter study of backto-back video colonoscopies. Endoscopy 2008;40:284-290.

14. Leufkens AM, van Oijen MG, Vleggaar FP, Siersema PD. Factors influencing the miss rate of polyps in a back-to-back colonoscopy study. Endoscopy 2012;44:470-475.

15. Hong SN, Sung IK, Kim JH, et al. The effect of the bowel preparation status on the risk of missing polyp and adenoma during screening colonoscopy: a tandem colonoscopic study. Clin Endosc 2012;45:404-411.
16. Ferrández A, Navarro M, Díez M, et al. Risk factors for advanced lesions undetected at prior colonoscopy: not always poor preparation. Endoscopy 2010;42:1071-1076.

17. Kim JH, Kim YS, Cheon JH, et al. Influence of the insertion time and number of polyps on miss rate in colonoscopy. Scand J Gastroenterol 2011;46:634-639.

18. Pohl H, Robertson DJ. Colorectal cancers detected after colonoscopy frequently result from missed lesions. Clin Gastroenterol Hepatol 2010;8:858-864.

19. Aronchick CA, Lipshutz WH, Wright SH, Dufrayne F, Bergman G. A novel tableted purgative for colonoscopic preparation: efficacy and safety comparisons with Colyte and Fleet PhosphoSoda. Gastrointest Endosc 2000;52:346-352.

20. Ng SC, Tsoi KK, Hirai HW, et al. The efficacy of cap-assisted colonoscopy in polyp detection and cecal intubation: a metaanalysis of randomized controlled trials. Am J Gastroenterol 2012;107:1165-1173.

21. Kondo S, Yamaji Y, Watabe $\mathrm{H}$, et al. A randomized controlled trial evaluating the usefulness of a transparent hood attached to the tip of the colonoscope. Am J Gastroenterol 2007;102:75-81.

22. Tsai FC, Strum WB. Prevalence of advanced adenomas in small and diminutive colon polyps using direct measurement of size. Dig Dis Sci 2011;56:2384-2388.

23. Rex DK, Cutler CS, Lemmel GT, et al. Colonoscopic miss rates of adenomas determined by back-to-back colonoscopies. Gastroenterology 1997;112:24-28.

24. Bianco MA, Cipolletta L, Rotondano G, et al. Prevalence of nonpolypoid colorectal neoplasia: an Italian multicenter observational study. Endoscopy 2010;42:279-285.

25. Martínez ME, Sampliner R, Marshall JR, Bhattacharyya AK, Reid ME, Alberts DS. Adenoma characteristics as risk factors for recurrence of advanced adenomas. Gastroenterology 2001;120:1077-1083.

26. Bonithon-Kopp C, Piard F, Fenger C, et al. Colorectal adenoma characteristics as predictors of recurrence. Dis Colon Rectum 2004;47:323-333. 